\title{
Utilisation of carbonating olivine for sustainable soil stabilisation
}

\begin{abstract}
This paper describes the first study demonstrating the potential of olivine as a soil stabiliser. Olivine has been shown to provide a reactive source of magnesium oxide capable of sequestering carbon dioxide. The effects of olivine additions on consistency limits, compaction characteristics and unconfined compressive strength (UCS) of soil are described. The effect of carbon dioxide pressure, and carbonation period, on the UCS of olivine-treated soil is of great importance in defining treated properties. Results highlight the benefits of olivine in soft soil stabilisation with reference to the UCS. Use of $20 \%$ olivine decreased the plasticity index and optimum moisture content while increasing the maximum dry density of the soil. The greatest strength was developed after carbonation at $200 \mathrm{kPa}$ for $168 \mathrm{~h}$ in the soil containing 20\% olivine. Structural and compositional analysis using scanning electron microscopy and X-ray diffraction confirmed the benefits of olivine in terms of decreasing the discontinuity of soil. This was attributed to the crystallisation products responsible for strength development after carbonation, respectively. The paper is significant as it presents a more environmentally friendly method of stabilising soils compared with alternative methods using high embodied energy binders such as cement.
\end{abstract}

Keyword: Carbonation; Geoenvironment; Ground improvement 